\title{
Catalysts Containing Transition Metals on Nitrogen and Carbon Structures for Hydrogen Production through Saltwater Electrolysis
}

\author{
C. A. Degadillo Camargo ${ }^{\mathrm{a}}$, A. da Cunha Campos ${ }^{\mathrm{a}}$, O. Beruski ${ }^{\mathrm{b}}$, T. Lopes ${ }^{\mathrm{a}, \mathrm{b}}$ \\ a Nuclear and Energy Research Institute, São Paulo SP, 05508-000, Brazil \\ ${ }^{\mathrm{b}}$ Escola Politécnica, University of São Paulo, São Paulo SP, 05508-010, Brazil
}

When hydrogen is produced by electrolysis the possibility of water stress in some populations and scarcity of precious metals for catalyst production are seen as future barriers. The use of nonprecious metal catalysts allied to direct saltwater splitting reduce the pressure on scarce resources. Here, four Metal-Nitrogen-Carbon (M-N-C) catalysts were synthesized with metal salts of $\mathrm{Co}, \mathrm{Fe}, \mathrm{Ni}$ and FeNi, with 1,5-diaminonhaptalene as $\mathrm{N}-\mathrm{C}$ source. These catalysts were compared with a blank $\mathrm{N}-\mathrm{C}$ without metal and a Pt/C commercial catalyst. Tests were conducted in electrolyte solution $0.5 \mathrm{M}$ of $\mathrm{H}_{2} \mathrm{SO}_{4}$ and $0.5 \mathrm{M}$ of $\mathrm{NaCl}$. Results showed limited activity towards Hydrogen Evolution Reaction (HER) compared with Pt/C and other non-precious metal catalysts. Nevertheless, points out trends for better catalyst synthesis as improved activity of FeNi catalyst in acidic media and saltwater.

\section{Introduction}

The energetic and economic dependencies on fossil fuels, and the need of reducing greenhouse gas (GHG) emissions to mitigate climate change, are concerns that have increased interest on alternatives to produce, store and transport energy. Hydrogen gas, as an energy carrier, is promising as it does not produce GHG emissions in the local of utilization and can be obtained from several sources of low, neutral or negative $\mathrm{CO}_{2}$ intensities [1] [2]. To enable the use of $\mathrm{H}_{2}$ as a clean and sustainable carrier, its production through water electrolysis is a crucial pathway as it enables $\mathrm{H}_{2}$ production using only water and electricity [3].

However, freshwater availability, essential to this process, hinders its wide application [4]. Only $0.5 \%$ of the water on Earth is freshwater, $\approx 93000 \mathrm{~km}^{3}$, while the global demand in 2019 was around $4600 \mathrm{~km}^{3}, 70 \%$ due to agriculture and $20 \%$ to industry. By 2050 , it is expected that the demand in both areas will increase, as food demand will grow around $60 \%$ and water for manufacture by $400 \%$, meanwhile available freshwater diminishes every day because of pollution [5]. In contrasts, seawater is $96 \%$ of the water on the planet and can be considered almost as an unlimited resource. [4]

There are two ways of using seawater in an electrolysis process, the first being through water desalinization, and the second is through adequation of available electrolyzers to this electrolyte. Regarding direct use, a major challenge concerns the catalysts [4]. For 
hydrogen evolution reaction (HER), on the cathode, catalysts are usually made of precious metals such as platinum. This metal is expensive, limited, and susceptible to poisoning by chloride [6], or even small quantities of hydrogen sulfide [7], nitrous oxides and aromatic hydrocarbons from biologic and human activity [8] Likewise, for oxygen evolution reaction (OER) in the anode, chloride ions are corrosive and compete with oxygen, compromising catalytic activity [6]. Alternatively, metal-coordinated nitrogen-carbon nanostructures (M-N-C where $\mathrm{M}$ is a metal atom) have proven to be resistant to poisoning by these substances [8]. The number of studies on the use of this class of materials in HER is relatively low, although the results obtained in recent years show the possibility of effective use of this kind of catalyst for water electrolysis [9], while even fewer studies are available for saltwater and its progress has been limited. [10] [11]

To study their potential for saltwater electrolysis, five materials were synthesized using 1,5-diaminonaphthalene (1,5-DAN), as nitrogen and carbon precursor, and metal sulfate salts of $\mathrm{Ni}, \mathrm{Fe}, \mathrm{Ni}$ and $\mathrm{Fe}$ addition, as metal ions sources. The metals were compared with a commercial catalyst comprising $40 \% \mathrm{wt} \mathrm{Pt} / \mathrm{C}$. The influence of the metal salt on HER activity was measured in $\mathrm{H}_{2} \mathrm{SO}_{4}$ and $\mathrm{NaCl} 0.5 \mathrm{M}$ medium.

\section{Experimental}

\section{Catalyst synthesis}

The preparation of the catalyst consisted of three stages, the first being the oxidative polymerization that turned 1,5-DAN monomers into oligomers, which then undergo a drying process, forming a self-assembly of polymer microspheres. To form a catalyst with a high surface area, a first pyrolysis was performed, followed by an acid bath to remove metals not integrated in the structure. Finally, a second pyrolysis was performed [8] [12].

The oxidative polymerization was made by dissolving $200 \mathrm{mg}$ of 1,5 DAN (98\% Alfa Aesar) in $100 \mathrm{ml}$ of ethanol (Absolute ethanol Merck) into a jacketed reactor at room temperature. After 5 minutes of magnetic agitation was added the metallic salt, previously dissolved in $8 \mathrm{ml}$ of ultrapure water MilliQ $18.2 \mathrm{M} \Omega \mathrm{cm}$. The salts used were $\mathrm{NiSO}_{4} \cdot 6 \mathrm{H} 2 \mathrm{O}$ $\left(8.96 \mathrm{mg}\right.$ ) and $\mathrm{Fe} \mathrm{SO}_{4} .7 \mathrm{H}_{2} \mathrm{O}(9.96 \mathrm{mg}$ ) (all of them Sigma Aldrich $\geq 99 \%$ ), the masses correspond to $1 \%$ of each metal of the added 1,5 DAN. The oxidizing agent, $200 \mathrm{mg}$ of ammonium persulfate (98\% Sigma Aldrich) dissolved in $4 \mathrm{ml}$ of ultrapure water MilliQ $18.2 \mathrm{M} \Omega \mathrm{cm}$ was added after five minutes under constant magnetic agitation. The reaction was allowed to happen during $22 \mathrm{~h}$, then, the solution was vacuum filtered using a hydrophilic filter Omnipore PTFE TM with $0.45 \mu \mathrm{m}$ pore diameter, the filter cake was washed alternating water and ethanol until the liquid filtered was pristine. Finally, the solid cake formed by oligomers was dried for $8 \mathrm{~h}$ at $100{ }^{\circ} \mathrm{C}$ into a drying oven.

To perform the pyrolysis, it was necessary to make a conditioning protocol of the alumina boat crucibles, samples and oven atmosphere. The conditioning started with the empty boat crucible at $400^{\circ} \mathrm{C}$ for two hours at a heating ramp of $20 \mathrm{C} / \mathrm{min}$ with open oven. After cooling, the sample was transferred to the boat crucible, and it was introduced into the oven with argon flux of $200 \mathrm{~mL} / \mathrm{min}$ for 1 hour to assure an inert atmosphere. Then, the flux was fixed at $50 \mathrm{~mL} / \mathrm{min}$ and the oven temperature set at $300 \mathrm{C}^{\circ}$ for 1 hour, at a 


\section{9th ECS Meeting}

heating ramp of $20 \mathrm{C} / \mathrm{min}$, to remove water from the sample. Afterwards, the first pyrolysis started by setting the temperature at $950 \mathrm{C}^{\circ}$ for 2 hours at a heating ramp of 20 $\mathrm{C} / \mathrm{min}$. The sample was then cooled to room temperature followed by an acid treatment with $\mathrm{H}_{2} \mathrm{SO}_{4}$ reflux at $80 \mathrm{C}^{\circ}$ for $8 \mathrm{~h}$ with magnetic agitation at 500rpm. The sample was filtered and washed with water and dried at $100 \mathrm{C}^{\circ}$ for $8 \mathrm{~h}$. The second pyrolysis was set to $900 \mathrm{C}^{\circ}$ for 2 hours also at $20^{\circ} \mathrm{C} / \mathrm{min}$, to form the finished catalyst.

\section{Electrochemical measurements}

The electrochemical measurements were made using the linear sweep voltammetry (LSV) technique with a potenciostat Biologic SP-300, and a rotating ring disk electrode (RDE), the disk being a vitreous carbon electrode with $5 \mathrm{~mm}$ diameter and the ring a $\mathrm{Pt}$ electrode. To deposit the catalyst onto the electrode it was necessary to disperse $1 \% \mathrm{wt}$ of the sample catalyst into a 1:1 volume mixture of isopropanol and ultrapure $\mathrm{H} 2 \mathrm{O}$ (MilliQ $18.2 \mathrm{M} \Omega \mathrm{cm}$ ) and a Nafion to catalyst weight ratio of $1: 1$. The catalyst load was of $0.27 \mathrm{mg} \mathrm{cm}^{-2}$ [13]. The ink solution was mixed under sonication in an ice bath during 30 min before finally being cast $7,16 \mu 1$. [14]

To avoid overlapping and assure stable measurements, a conditioning procedure was executed for the catalyst layer. This was made in order to remove bubbles from the catalyst layer, turning it hydrophilic, allowing a completely wet surface. The procedure consisted of continuous cycling, in the potential range of between 1.050 and $-0.400 \mathrm{~V}$ vs. reversible hydrogen electrode (RHE), alternating between: 20 cycles at $100 \mathrm{mV} / \mathrm{s}, 10$ cycles at 10 $\mathrm{mV} / \mathrm{s}$, both in an argon-saturated solution, and 6 cycles at $5 \mathrm{mV} / \mathrm{s}$ in an oxygen-saturated solution.

The measures were performed in two different electrolytes, $0.5 \mathrm{M}^{\circ} \mathrm{H}_{2} \mathrm{SO}_{4}$ and $0.5 \mathrm{M}$ of $\mathrm{NaCl}$. To measure the catalytic activity of each catalyst towards HER in both electrolytes, LSV measurements were performed between 0.200 and $-0.300 \mathrm{~V}$ vs RHE at a scan rate of $2 \mathrm{mV} / \mathrm{s}$. The sweep was repeated 4 times for each catalyst. The ring electrode was held fixed at $0.300 \mathrm{~V}$ vs RHE, where the reaction corresponds to the hydrogen oxidation reaction (HOR) from the $\mathrm{H}_{2}$ generated at the disk. This process was carried at different rotation frequencies: 1400,1600 and $1800 \mathrm{rpm}$, to qualitatively study the effect of mass transfer on the reactions.

\section{Data processing}

Capacitance and Ohmic Drop correction. The capacitance value was assumed as the final vertical value of the current at the starting point of the voltammogram. The baseline for Tafel slope, overpotential and onset potential was taken as the extrapolation of the linear current between the capacitance and the reaction faradaic process beginning between 150 $\mathrm{V}$ and $-0,050 \mathrm{~V}$ in the LSV excluding Pt in both media, and FeNi because of the earlier beginning of the reaction and complexity of the curves. [15] [16] [17] 
Tafel slope. The Tafel slope is a parameter related to the reaction kinetics, from a limiting case of the Butler-Volmer equation. It describes the exponential relationship between current density and electrode potential, given by the Tafel equation [18] :

$$
\eta=a+b \log j=\frac{2.3 R T}{\alpha n F} \log j_{0}-\frac{2.3 R T}{\alpha n F} \log j
$$

Where $\eta$ is the Overpotential, it means the difference between the applied potential and the thermodynamic potential of the reaction, $b$ is the Tafel coefficient, $R$ is the universal constant of gases, $T$ is temperature, $n$ is the number of transferred electrons, $\alpha$ is the transfer coefficient, $\mathrm{j}$ is the current density and $\mathrm{j}_{0}$ is the exchange current density i.e., the current value at the thermodynamic potential [18]. The Tafel constant is an important indicator of the reaction kinetics, usually a smaller Tafel constant indicates that the current density increases more quickly with a smaller overpotential, which indicates favorable electrochemical kinetics in terms of catalysis. To obtain the Taffel coefficient, the logarithm of current data, in the final faradaic reaction region (interval of -0.200 to $0.300 \mathrm{~V}$ for HER), was adjusted through a linear regression, the coefficient being used to obtain the Tafel slope and exchange current density. [18] [19] The value was obtained by the intersection of the linear regression of the logarithm of currents of the faradic processes between $-0,250$ and $-0,300 \mathrm{~V}$

Overpotential. Thermodynamically, water splitting could occur around $1.229 \mathrm{~V}$. However, a higher potential is necessary to achieve significant rates of reaction. This difference is called overpotential, or more accurately, activation overpotential. The most widely used parameter to demonstrate such overpotential is the electrode potential necessary to achieve a current density of $10 \mathrm{~mA} / \mathrm{cm}^{2}$. However, due to the current magnitudes achieved by the catalysts shown here, we used the electrode potential necessary to achieve $0.100 \mathrm{~mA} / \mathrm{cm}^{2}$. [15] [19]

Onset potential. The onset potential is usually defined as the point where current densities $j$ depart from zero for the desired reaction. However, the currents at this point are low and difficult to determine. [20] Here is used a common approximation consisting of the intersection of the linear regressions of the faradaic current line and the baseline of nonfaradaic current. [21] [22] [23] 


\section{Results and discussion}

First and foremost, it should be pointed out that the LSVs using rotation frequencies did not show an effect on the reaction rate due to improved mass transport. Thus, only one rotation frequency will be shown, $1800 \mathrm{rpm}$, for both HER and HOR and their respective $\mathrm{H}_{2} \mathrm{SO}_{4}$ and $\mathrm{NaCl}$ media results.
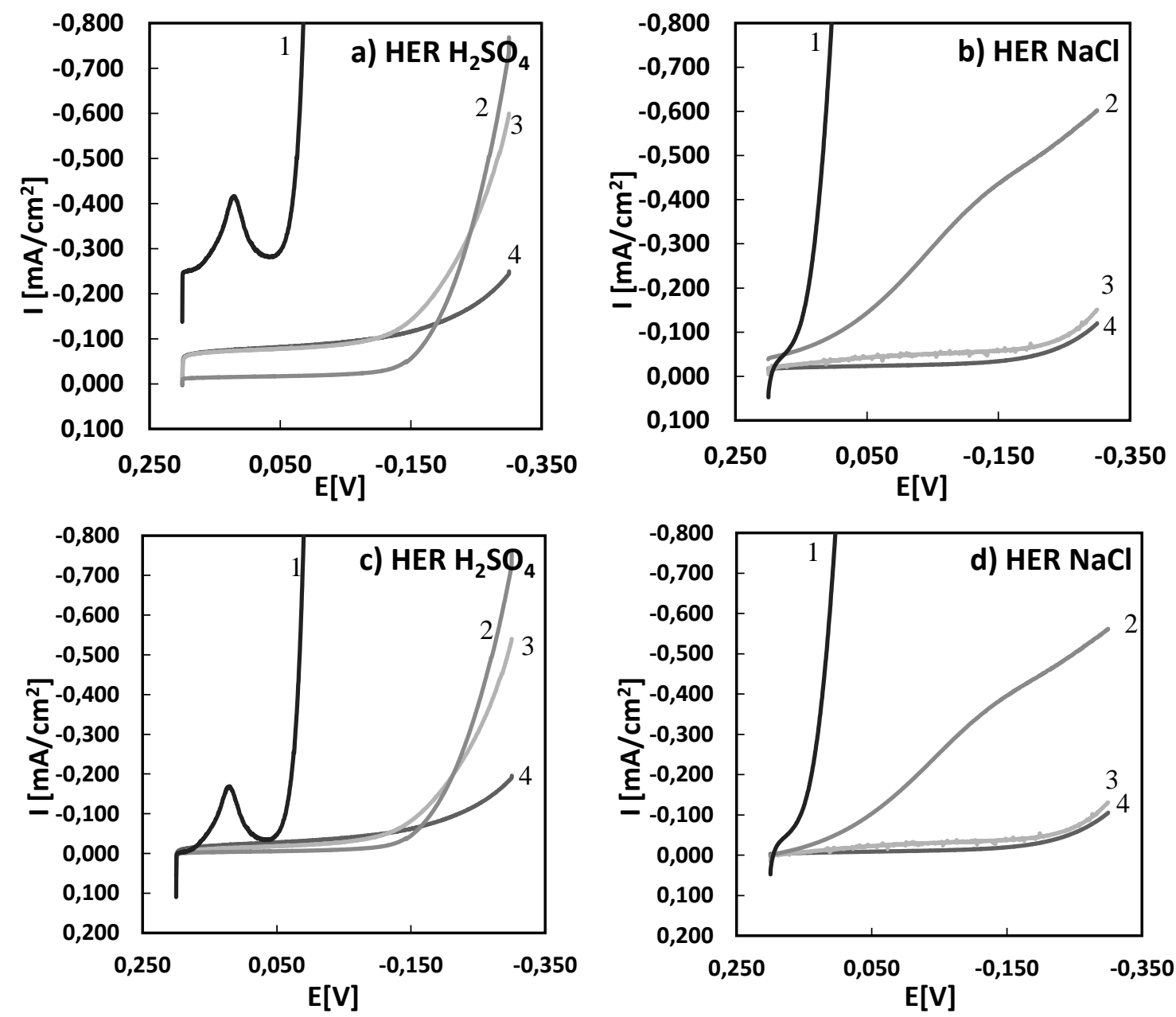

Figure 1. Disk LSV in the region of HER in saline medium at $1800 \mathrm{rpm}$ and adjusted to geometric area of the electrode with $0.5 \mathrm{~cm}$ of diameter. a) acidic medium, b) saltwater and the capacitance correction c) acidic medium d) saltwater Line descriptions: 1: Pt/C, 2: FeNi-N-C, 3: Fe-N-C, 4: Ni-N-C. Error bars represent the standard deviation of three measuremts.

The graphics a) and b) in Figure 1. show that the LSV curves in acidic media had higher capacitance than saltwater solution. Other studies on nitrogen carbon surfaces with different electrolyte solutions points out the anion, $\mathrm{SO}_{4}{ }^{-2}$, is responsible of this feature. [24]. Also, in acidic media, on graphics a) and c) outstand out an adsorption peak in current at approximately $0,100 \mathrm{~V}$. It is also possible to see, in the same figure, that even without correction, and despite of $\mathrm{pH}$ and electrolyte differences, there is a tendency to conserve the order of the current curves, the order from the catalysts that reaches higher currents to the one with the lowest currents is $\mathrm{Pt} / \mathrm{C}>\mathrm{FeNi}-\mathrm{N}-\mathrm{C}>\mathrm{Fe}-\mathrm{N}-\mathrm{C}>\mathrm{Ni}-\mathrm{N}-\mathrm{C}$. 
Among the synthesized catalysts FeNi-N-C apparently has one of the highest activities in both saline and acidic media. Several studies on diverse kinds of metal-N-C catalysts points out a multi-metallic synergy that increases the activity towards the HER reaction [25] [26] [27]. It is therefore necessary to assess if there is an actual improvement in activity when both metals are present in the catalyst, or if this activity increment is only the result of the additive number of active sites. Figure 3 shows the comparison between the sum of $\mathrm{Ni}$ and $\mathrm{Fe} \mathrm{LSVs}$ and for the NiFe catalyst. Currents reached higher values for the synthesized catalysts in $\mathrm{NaCl}$ and were very close to each other in acidic medium. Table 1 summarizes the Tafel slopes, also shown in Figure 4, exchange current density and overpotential (at $0.1 \mathrm{~mA} / \mathrm{cm}^{2}$ ), in order to clarify the comparison.
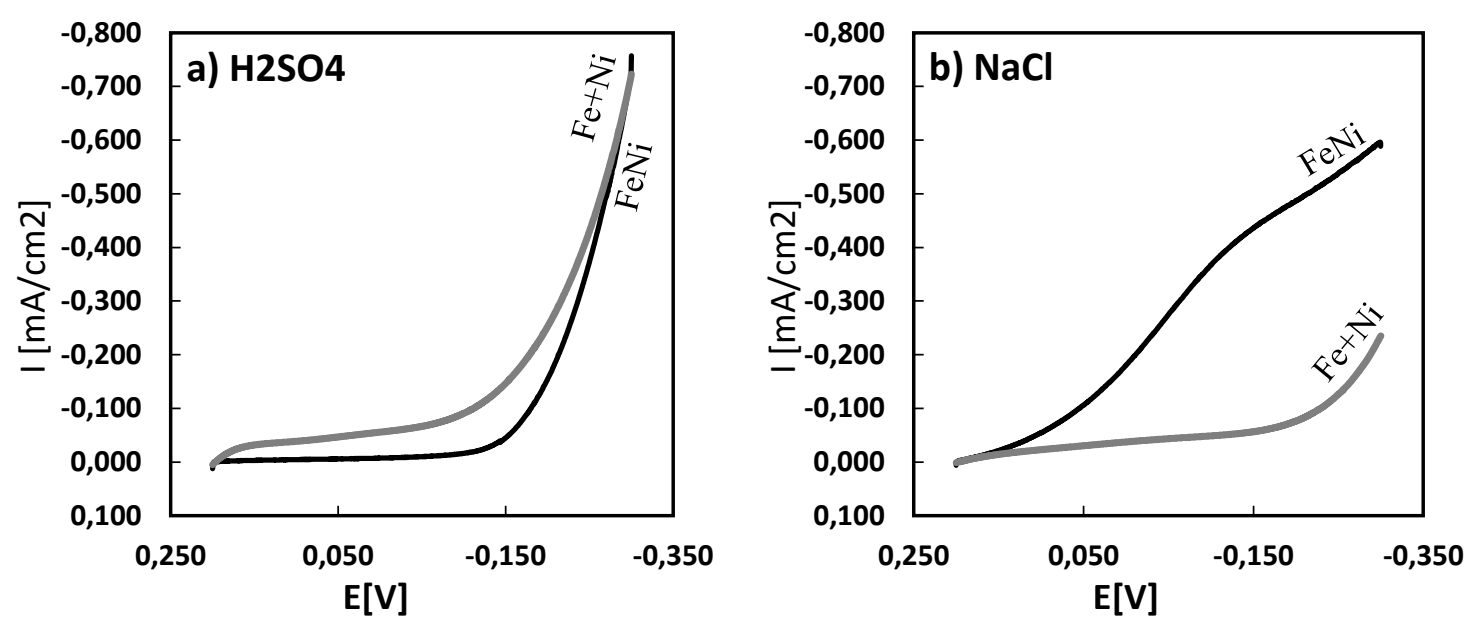

Figure 3. LSV of HER for comparison between the sum of Ni and Fe catalysts activity (grey line) and the catalyst synthesized with the Ni and Fe salts directly (Black line). a) In acidic medium and b) in saline medium.
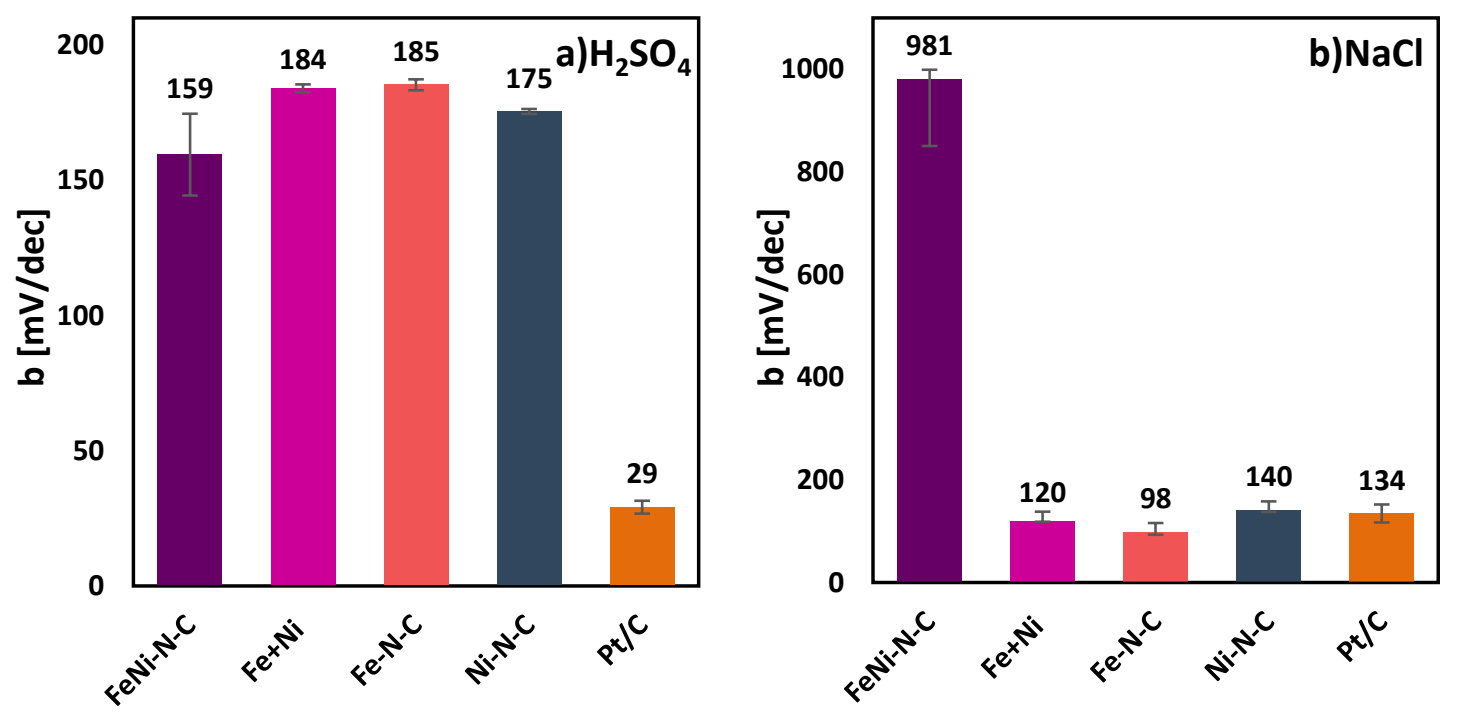

Figure 4. Tafel slopes of the syntetized catalyst in acidic a) and saltwater b). 


\section{9th ECS Meeting}

The tafel slope values of the HER for the synthesized catalysts and $\mathrm{Pt} / \mathrm{C}$ is shown in Figure 4. The Tafel slope is an indicative of the rate determaning step (rds) of reaction mechanis. When Buttler-Volmer equation is used to determine kinetics, the values of Tafel slope near $118 \mathrm{mV} / \mathrm{dec}$ are thinking to indicate the discharge reaction as rds (Volmer step), near between $39 \mathrm{mV} / \mathrm{dec}$, electrochemical desorption (Heyrovsky Step) and $30 \mathrm{mv} / \mathrm{dec}$ recombination (Tafel step) for traditional Pt catalysts. Nevertheless, Carbon catalyst activated with heteroatoms usually present Tafel slopes between 91-206 mV/dec in acidic media and 145-209 mV/dec in alkaline media. [28] [29] [30] These values are close to the obtained in this study, excluding FeNi-N-C in saltwater with a notorious value of $981 \mathrm{mV} / \mathrm{dec}$. This exclusion could be related to the complexity of the bimetallic behavior on this study, that difficult calculation of electrochemical parameters and appears to represent the overlapping of other processes such as hydrogen adsorption and an unclear double layer region. This complexity is also visible to a lesser extent in Fe catalyst. Figure 4 shows a reduction of Tafel slopes on almost all synthesized catalysts, with the exception of FeNi-N-C, when going from acidic to saline media. [31] On the other hand, according to Table 1, larger exchange current density values are seen on acidic media.

Now, comparing the addition of Fe and Ni individual parameters in acidic medium, the Tafel slope for the final synthesised FeNi catalyst is lower, while retaining a higher exchange current density. In addition, when assessing the joint response of both $\mathrm{Fe}$ and $\mathrm{Ni}$ catalysts, the FeNi catalyst still shows superior performance. In saline medium the high Tafel slope indicates a poor activity of the FeNi catalysts, however its high exchange current density and low overpotential are better than those of the $\mathrm{Pt} / \mathrm{C}$ catalyst. Both media are indicative of the existence of an important synergic effect of the bimetallic surface of HER activity.

TABLE I. Electrochemical parameters of the synthesized catalysts and other literature catalysts

\begin{tabular}{|c|c|c|c|c|c|c|c|c|c|c|c|}
\hline & \multicolumn{5}{|c|}{ Acidic media $0.5 \mathrm{M} \mathrm{H}_{2} \mathrm{SO}_{4}$} & \multicolumn{6}{|c|}{0.5 M NaCl / Seawater neutral pH } \\
\hline Catalyst & $b$ & $\boldsymbol{j}_{0}$ & $\mathbf{E}_{0}$ & $\eta$ & & Catalyst & $b$ & $\boldsymbol{j}_{0}$ & $\mathbf{E}_{0}$ & $\eta$ & \\
\hline FeNi-N-C & 159 & 1,019 & -205 & $-196^{*}$ & - & FeNi-N-C & 981 & 0,475 & 149 & 52 & - \\
\hline $\mathrm{Fe}+\mathrm{Ni}$ & 184 & 0,0991 & -196 & $-173^{*}$ & - & $\mathrm{Fe}+\mathrm{Ni}$ & 120 & 0,039 & -222 & 272 & - \\
\hline Fe-N-C & 185 & 0,286 & -195 & $-186^{*}$ & - & Fe-N-C & 98 & 0,0164 & -236 & $<-300^{*}$ & - \\
\hline $\mathrm{Ni}-\mathrm{N}-\mathrm{C}$ & 175 & 0,792 & -199 & $-282^{*}$ & - & $\mathrm{Ni}-\mathrm{N}-\mathrm{C}$ & 140 & 0,0409 & -214 & $299^{*}$ & - \\
\hline $\mathbf{P t} / \mathbf{C}$ & 29 & 0,8683 & 67 & $30^{*}$ & - & $\mathbf{P t} / \mathbf{C}$ & 134 & 0,429 & 67 & 142 & - \\
\hline $\mathrm{Pt} / \mathrm{C}$ & 30 & - & - & -34 & [32] & & & & & & \\
\hline $\begin{array}{c}\text { Co-N }{ }_{\text {PAIN- }}^{-} \\
\mathrm{C}\end{array}$ & 132 & 1,9 & - & $-77^{* *}$ & [9] & NiMoN & - & - & - & $-339^{* / *}$ & [33] \\
\hline $\begin{array}{c}\text { Co-U- } \\
\text { CNT-900 }\end{array}$ & 79 & - & - & $-270^{* * *}$ & [34] & $\begin{array}{l}\text { U-CNT- } \\
900\end{array}$ & 159 & - & - & -250 & [34] \\
\hline CoMoP@C & 50 & 1,21 & - & -41 & [32] & $\mathrm{Ti} / \mathrm{NiCo}$ & 167 & 0,00476 & -390 & - & [35] \\
\hline & & & & & & $\mathrm{Ti} / \mathrm{Ni}$ & 187 & 0,00139 & -570 & - & [35] \\
\hline
\end{tabular}

-Units: Tafel slope (b) (mV/dec), exchange current density $\left(\mathrm{j}_{0}\right)\left(\mathrm{mA} / \mathrm{cm}^{2}\right)$, Onset potential $\left(\mathrm{E}_{0}\right)$ and overpotential $\eta(\mathrm{mV})$.

-For overpotential: ${ }^{*}$ Values calculated at $0,100 \mathrm{~mA} / \mathrm{cm}^{2},{ }^{* *}$ Values calculated at $5 \mathrm{~mA} / \mathrm{cm}^{2}$,

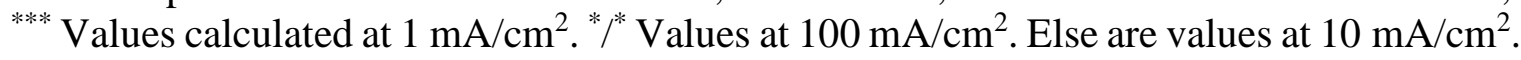
-Bold titles indicate catalysts synthetized on this work. 
According to Table1. The Pt calculated electrochemical parameters are similar to those found in literature. In the other hand, among the catalyst found in literature there was not many M-N-C catalyst, and excluding Co catalyst, there were not found monometallic catalyst for HER in saltwater, seawater or $\mathrm{NaCl}$ solution. There were found few saltwater or acid Fe containing catalysts which are most commonly used in alkaline media [33] [36]. The catalyst synthesized on this study need further improvement to be comparable with other non-precious metal catalyst such as Co-N $\mathrm{NAIN}_{\mathrm{N}} \mathrm{C}$ and Co-U-CNT-900. However, proved to perform better than the cited alloy catalysts $\mathrm{Ti} / \mathrm{NiCo}$ and $\mathrm{Ti} / \mathrm{Ni}$. This data must be adjusted to specific active site area to be really comparable to other catalysts.

\section{Summary and conclusions}

In summary, FeNi-N-C catalysts showed the biggening of a path for direct saltwater electrolysis catalysts, a better understanding of the catalysts kinetics in saltwater is necessary to develop improved active sites and understanding of the different phenomena contributions on the complex transition metal and bimetallic activity and interaction with the electrolytes.

\section{Acknowledgments}

To FAPESP - São Paulo State Research Support Foundation (Process n 2014/22130-6 and 2018 / 15327-9) for the essential financial support to carry out this research and to FUSPUniversity of Sao Paulo Support Foundation, project \#360248.

\section{References}

[1] V. Blagojević , D. Minić, D. Minić and J. Grbović Novaković. Hydrogen Economy: Modern Concepts, Challenges and Perspectives. Hydrogen Energy, Belgrado, IntechOpen, 2012. DOI: 10.5772/46098

[2] Y. Zhang and X. Zou. Noble metal-free hydrogen evolution catalysts for water splitting. Chemical Society Reviews, 44 (15). 2015. DOI: 10.1039/C4CS00448E

[3] IEA webstore. The Future of Hydrogen, Seizing today's opportunities. 2019.

[4] S. Dresp, . F. Dionigi, M. Klingenhof and . P. Strasser. Direct Electrolytic Splitting of Seawater: Opportunities and Challenges. ACS Energy Letters, 4, (4), 2019. DOI: $10.1021 /$ acsenergylett.9b00220

[5] A. Boretti and L. Rosa. Reassessing the projections of the World Water Development Report. npj Clean Water, 2, (15), 2019. DOI: 10.1038/s41545-019-0039-9

[6] J. Vos and M. Koper. Measurement of competition between oxygen evolution and chlorine evolution using rotating ring-disk electrode voltammetry. Journal of Electroanalytical Chemistry, 819, 2018. DOI: 10.1016/j.jelechem.2017.10.058

[7] V. A. Sethuraman and . J. W. .Weidner. Analysis of Sulfur Poisoning on a PEM Fuel Cell Electrode. Electrochimical acta, 55, (20), 2010. DOI: 10.1016/j.electacta.2010.05.004 
[8] D. Malko, T. Lopes, E. Symianakis $§ a$ and A. Kucernak. The intriguing poison tolerance of non-precious metal oxygen reduction reaction (ORR) catalysts. Journal of Materials Chemistry A, (4), 2016. DOI: 10.1039/C5TA05794A

[9] D. Mazur, O. Pariiska and Y. Kurys. Co-N-C electrocatalysts derived from nitrogen containing conjugated polymers for hydrogen evolution. Materials Today Proceedings, 6, 2019. DOI: 10.1016/j.matpr.2018.10.077

[10] L. Yu, Q. Zhu, . S. Song, B. McElhenny, D. Wang, C. Wu, Z. Qin, . J. Bao, Y. Yu, S. Chen and Z. Ren. Non-noble metal-nitride based electrocatalysts for highperformance alkaline seawater electrolysis. Nature Communications, 10, (5106), 2019. DOI: 10.1038/s41467-019-13092-7

[11] Y. Kuang, M. . J. Kenney, Y. Meng, W.-H. Hung, Y. Liu, J. E. Huang, R. Prasanna, P. Li, Y. Li and L. Wang. Solar-driven, highly sustained splitting of seawater into hydrogen and oxygen fuels. PNAS, 116, (14), 2019. DOI: 10.1073/pnas. 1900556116

[12] D. Malko. Electrocatalytic and catalytic oxygen reduction utilising transition metal and heteroatom doped carbon materials. 2016. DOI: 10.25560/56200

[13] D. Malko, A. Kucernak and T. Lopes. In situ electrochemical quantification of active sites in Fe-N/C non-precious metal catalysts. Nat Commun, 7, (13285), 2016. DOI: $10.1038 /$ ncomms13285

[14] I. Takahashi and S. S. Kocha. Examination of the activity and durability of PEMFC catalysts in liquid electrolytes. Journal of Power Sources, 195, (19) , 2010. DOI: 10.1016/j.jpowsour.2010.04.052

[15] A. J. Bard and L. R. Faulkner. Electrochemical methods Fundamentals and applications. 2nd Edition, Wiley, 2001. ISBN: 978-0-471-04372-0

[16] J. Hrbac , V. Halouzka, L. Trnko and J. Vacek. eL-Chem Viewer: A Freeware Package for the Analysis of Electroanalytical Data and Their Post-Acquisition Processing. Sensors, 14, (8), 2014. DOI: 10.3390/s140813943

[17] V. S. Muralidharan. VOLATMMETRY. 2018. [Online]. Available: https://www.researchgate.net/post/Can_anyone_explain_about_Tafel_plots_iR_cor rection_during_CV_measurements.

[18] J. González-Velasco, Métodos Experimentales en electroquímica, III, CULTIVALIBROS, 2012. ISBN: 978-8415661689

[19] J. Peng, W. Dong, Z. Wang, Y. Meng, W. Liu, P. Song and Z. Liu. Recent advances in 2D transition metal compounds for electrocatalytic full water splitting in neutral media. Materials today advances, 8, 2020. DOI: 10.1016/j.mtadv.2020.100081

[20] S. Chem, Advanced Nanomaterials for Electrochemical-Based Energy Conversion and Storage, Elsevier, 2020. ISBN: 978-0-12-814558-6

[21] Z.-F. Huang, J. Wang, . Y. Peng, C.-Y. Jung, A. Fisher and X. Wang. Design of Efficient Bifunctional Oxygen Reduction/Evolution Electrocatalyst: Recent Advances and Perspectives. Advanced Energy Materials, 7, (1700544), 2017. DOI: 10.1002/aenm.201700544

[22] T.-N. Tran, M. Young Song, K. Pal Singh, D. -S. Yang and J. -S. Yu. Ironpolypyrrole electrocatalyst with remarkable activity and stability for ORR in both alkaline and acidic conditions: a comprehensive assessment of catalyst preparation sequence. Journal of Material Chemistry A, 4, 2016. DOI: 10.1039/C6TA01543C 


\section{9th ECS Meeting}

[23] N. Elgrishi, K. J. Rountree, B. . D. McCarthy, . E. . S. Rountree and T. . T. Eisenhart. A Practical Beginner's Guide to Cyclic Voltammetry. Journal of Chemical Education, 95, (2), 2017. DOI: 10.1021/acs.jchemed.7b00361

[24] Y.-m. Cai, Z.-y. Qin and L. Chen. Effect of electrolytes on electrochemical properties of graphene sheet covered with polypyrrole thin layer. Progress in Natural Science , 21, (6), 2011. DOI: 10.1016/S1002-0071(12)60083-5

[25] W. Pei, S. Zhou, . Y. Bai and J. Zhao. N-doped graphitic carbon materials hybridized with transition metals (compounds) for hydrogen evolution reaction: Understanding the synergistic effect from atomistic level. Carbon, 133, 2018. DOI: 10.1016/j.carbon.2018.03.043

[26] S. Qi, J. Wang, X. Song, Y. Fan, W. Li, A. Du and M. Zhao. Synergistic trifunctional electrocatalysis of pyridinic nitrogen and single transition-metal atoms anchored on pyrazine-modified graphdiyne. Science Bulletin, 65, (12), 2020. DOI: $10.1016 /$ j.scib.2020.03.021

[27] L. Zhang, . W. Liu, Y. Dou, . Z. Du and M. Shao. The Role of Transition Metal and Nitrogen in Metal-N-C Composites for Hydrogen Evolution Reaction at Universal pHs. 120, (51), Journal of Physical Chemistry C., 120, (51), 2016. DOI: $10.1021 /$ acs.jpcc.6b11782

[28] M. Zeng and Y. Li. Recent advances in heterogeneous electrocatalysts for the hydrogen evolution reaction. Journal of Materials Chemistry A., 3, (29) , 2015. DOI: doi.org/10.1039/C5TA02974K

[29] T. Shinagawa, . A. T. Garcia-Esparza and K. Takanabe. Insight on Tafel slopes from a microkinetic analysis of aqueous electrocatalysis for energy conversion. Scientific Reports, 5, (13801), 2015. DOI: 10.1038/srep13801

[30] J. Bockris, Modern Electrochemistry, Springer US, 1970. ISBN: 978-1-4613-4560-2

[31] H.-L. Choua, B.-J. Hwang and C.-L. Sun. Catalysis in Fuel Cells and Hydrogen Production. New and Future Developments in Catalysis, Elsevier, 2013. ISBN: 978-0-444-53880-2

[32] Y.-Y. Ma, C.-X. Wu, . X.-J. Feng, H.-Q. Tan, L.-K. Yan, Y. Liu, Z.-H. Kang, E.-B. Wanga and Y.-G. Li. Highly efficient hydrogen evolution from seawater by a lowcost and stable CoMoP@C electrocatalyst superior to $\mathrm{Pt} / \mathrm{C}$. Energy and Environmental Science, 10, (3), 2017. DOI: 10.1039/C6EE03768B

[33] L. Yu, Q. Zhu, S. Song, . B. McElhenny, . D. Wang, C. Wu, Z. Qin, J. Bao, Y. Yu, S. Chen and Z. Ren. Non-noble metal-nitride based electrocatalysts for highperformance alkaline seawater electrolysis. Nature Communications, 10, (5106), 2019. DOI: $10.1038 / \mathrm{s} 41467-019-13092-7$

[34] S. Gao, G.-D. Li, Y. Liu, H. Chen, L.-L. Feng, Y. Wang, M. Yang, D. Wang, S. Wang and $\mathrm{X}$. Zou. Electrocatalytic $\mathrm{H} 2$ production from seawater over Co, Ncodoped nanocarbons. Nanoscale, 7, 2015. DOI: 10.1039/C4NR04924A

[35] Y. Zhang, P. Li, X. Yang, W. Fa and S. Ge. High-efficiency and stable alloyed nickel based electrodes for hydrogen evolution by seawater splitting,. Journal of Alloys and Compounds., 732, 2018. DOI: 10.1016/j.jallcom.2017.10.194

[36] Y. Kuang, . M. J. Kenney, Y. Meng, W.-H. Hung, Y. Liu, J. E. Huang, R. Prasanna, P. Li, Y. Li , L. Wang, M.-C. Lin, M. . D. McGehee, X. Sun and H. Dai. Solar- 
239th ECS Meeting

driven, highly sustained splitting of seawater into hydrogen and oxygen fuels. PNAS, 116, (14), 2019. DOI: 10.1073/pnas.1900556116 